\title{
The Effect of Different Reading Tasks on Chinese Senior High School English Learners' Incidental vocabulary Acquisition
}

\author{
Qin $\mathrm{Xu}^{1}$, Lili Yan \\ School of Foreign Language, Henan University of Technology, Zhengzhou 450001, China \\ ${ }^{1}$ Email: $1803691705 @ q q . c o m$
}

\begin{abstract}
Based on the Involvement Load Hypothesis and from the perspective of involvement load and task type of the task design, this study aims to investigate the effects of task-induced involvement and different task types on incidental vocabulary acquisition in senior high school students. In this study, three parallel classes of Grade 10 from a senior high school in Xin County are selected as participants and they are divided as three parallel treatment groups assigned with three different reading tasks respectively. The three tasks are multiple choice questions after reading comprehension, gap-filling after looking up target words in the dictionary, and answering related questions with original sentences. Upon finishing the tasks, an immediate vocabulary test and a delayed vocabulary test one week later are carried out. Both quantitative analysis and qualitative analysis are applied to analyze the data collected. Major research findings are presented below: (1) Reading tasks with higher involvement loads generally lead to better initial word gains and delayed word gains than tasks with lower involvement loads but both fail to bring about satisfying retention effect of vocabulary. (2) With the same involvement load, there is no significant difference between the effect of the interpretive task and the productive task on immediate word acquisition while as for the effect on word retention, the productive task appears much superior to the interpretive task. The results of the present experiment partially supported the Involvement Load Hypothesis. Meanwhile, some pedagogical implications were suggested to improve vocabulary teaching in senior high school.
\end{abstract}

Keywords: Incidental vocabulary acquisition, reading task, involvement load

\section{Introduction}

As an indispensable part of language, vocabulary is the basis of any other Languages skill including listening, speaking, reading, writing and translation. As the base of language, vocabulary plays a momentous part in communicating with language. Scholars have had quite a few discussion and research on vocabulary acquisition from different perspectives, including "Incidental Vocabulary Acquisition (IVA)". The concept of Incident Vocabulary Acquisition was first proposed by Nagy et al.(1985) in their study of children learning mother tongue vocabulary. They pointed out that the best way of vocabulary learning is to acquire new words incidentally through reading in that people can never cover all the vocabulary by virtue of direct learning considering the large quantity of first language vocabulary.

Second language incidental vocabulary acquisition has a relatively wide research scope. Usually, there exists certain degree of incidental acquisition while cultivating various language skills like listening, speaking, reading and writing. However, in the domestic English learning environment in senior high school, students obtain the acquisition of language mainly by way of reading. Reading can enlarge vocabulary generally because there are vocabularies incidentally acquired through reading. And reading tasks exert a great influence on the effectiveness of incidental vocabulary acquisition.

Laufer and Hulstijn (2001) put forward the Involvement Load Hypothesis and made it the criterion to measure the impact of reading tasks on vocabulary acquisition. The basic notion of the Involvement Load Hypothesis is that "the effectiveness of a task is determined by the involvement load it induces" (Lauger \& Hulstijn, 2001) and the "involvement load" is developed into a motivational-cognitive construct incorporating three factors: need, search and evaluation. They believe that different tasks facilitate learners to conduct cognitive processing to different extents, which leads to different acquisition effects. The higher involvement load the processing tasks carry, the better incidental acquisition will be.

A lot of studies associated with task-based learning and teaching indicate that tasks occupy an 
important position in current second language research as well as in language pedagogy (Ellis, 2003). Different types of reading tasks such as interpretive tasks (dictionary-consultation and gap-filling task) and productive tasks (question and answer task, retelling, making sentences) tend to cause different levels of discourse information processing, which may further exert different effects on incidental vocabulary acquisition ( Shuhua Gai, 2003).

Scholars from home and abroad have successively carried out tests on the Involvement Load Hypothesis. However, the results of some empirical studies are not always in correspondence with the research findings of Laufer and Hulstijn, indicating that there exists no constant positive correlation between involvement load and acquisition effect. Further discussion and research, therefore, is necessary to be conducted on the hypothesis. At the same time, the present empirical studies on incidental vocabulary acquisition mainly regard intermediate and advanced English learners as research subjects, other learner group taking up a relatively small proportion.

As a result, this study sets students from senior high school as the subjects and tries to investigate the effects of different reading tasks on incidental vocabulary acquisition based on the Involvement Load Hypothesis. It seeks for the characteristics of second language learners in senior high school while acquiring vocabulary incidentally, providing some inspiration for second language vocabulary teaching, helping teachers to scientifically design and utilize reading tasks in the practical teaching system and promoting students' language learning.

\section{$2 \quad$ Methodology}

\section{$2.1 \quad$ Research Questions}

This study derives the first research question from the assumption of the Involvement Load Hypothesis that the effect of incidental vocabulary acquisition and retention are dependent on the involvement load induced by tasks, attempting to investigate the impact of different reading tasks on incidental vocabulary acquisition among high school students from the perspective of involvement load. Then, the second research question comes from the perspective of task type to make a comparison between the vocabulary learning effect through interpretive and productive tasks.

Therefore, the research questions addressed are as follows:

1. How do reading tasks with different involvement loads influence incidental vocabulary acquisition among senior high school students?

2. In terms of initial word gains and word retention, what are the differences between the effects of reading tasks of different types (interpretive and productive) on senior high school students' incidental vocabulary acquisition?

\subsection{Participants}

The participants in the study are Grade 10 students from a four-star senior high school in Xin County of Henan Province. All these students are Chinese learners of English and have learned English for about 7 years. They come from three parallel classes so that it can be ensured the English proficiency and learning capacity among the three classes are almost identical, with 52 students in class 1, 48 students in class 2 and 52 students in class 3. Each class is treated as one experimental group assigned to one kind of reading task. Finally, 30 samples in each group are collected, the other regarded as invalid samples considering the effectiveness of participants' task completion and their engagement in the task.

\subsection{Instruments}

The research instruments involve six parts: the reading material, target words, task design, tests.

\subsubsection{Reading Materials}

The reading material "A successful life" comes from English Weekly, a kind of learning aid newspaper enjoying large scale of subscription and once ranking the first in the comprehensive evaluation of publishing quality among education and counselling newspaper. With the goal of being updated and synchronous to lesson periods, English Weekly edits and publishes multi-level reading passages with high quality, which corresponds with students as well as teachers in different grades. This topic is familiar to 
students so that it indicates a fairly high readability. Then, the participants who are Grade 10 students have little possibility to access this material as it is derived from English Weekly of Grade 11. As for the degree of difficulty, the passage is adapted in combination with advice from several senior teachers as well as the results of pilot study, trying to correspond with participants' competence. And the adaptation includes substitution of low-frequency words, abridgement of passage and deletion of long and complicated sentences. Although the material from Grade11 seems to be above the level of Grade 10 students, the main obstacle to Grade 10 Students results from vocabulary size because students in both grades are now in the beginning stage of learning, which suggests a quite small proportion of reading comprehension strategies that are usually involved in later learning stages. As is pointed out by Laufer, only if the ratio of unknown words in the whole text is lower than $5 \%$ can learners comprehended the text thoroughly so as to invite incidental vocabulary acquisition to take place. Accordingly, some unfamiliar words are substituted, ensuring that there are at most $5 \%$ of new words, which creates moderate difficulty for participants.

\subsubsection{Target Words}

Ten target words from the reading material are selected in the light of criteria as follows. The words are unfamiliar to participants. To ensure all the target words are unknown to participants, the designer carried out a pretest among top students from another parallel class who will not attend the study. In the pretest, 16 words are chosen and students are required to tick out those they have already known. Then, 12 words are selected to be target words in the pilot study. A variety of word classes are to feature the target words. According to Ellis \& Beaton (1993), nouns can be acquired most easily while verbs and adverbs are more difficult to learn. Through further refinement of the text after the pilot study, 10 target words finally chosen: gaze, criticism, utilizable, perturbing, self-image, identity, presumably, distort, narcissism, accurately. Among these words, there are 4 nouns, 2 verbs, 2 adverbs and 2 adjectives.

\subsubsection{Task Design}

Different reading tasks will generate different depths of processing in vocabulary acquisition. According to Laufer \& Hulstijn (2001), the level of processing can be measured by the involvement load from the perspective of need, search and evaluation. This study designs three tasks to investigate how reading tasks with different involvement loads as well as different task types affect incidental vocabulary acquisition.

Task 1 is reading comprehension questions with glossary. Participants are requested to read through the passage and then finish five multiple choice questions followed. Ten target words are glossed with Chinese meanings and part of speech. While the main purpose of the five questions is to check participants' understanding of the text, they are relevant to target words. Therefore, a total involvement load should be 1. Task 2 is gap-filling after looking up target words in the dictionary. The passage is provided with ten target words bold and underlined, and participants need to consult the dictionary and then complete a task-based reading exercise with 16 blanks using target words and some other words. So, a total involvement load index should be 3 . Task 3 is answering questions with original sentences. Students are demanded to read the passage and answer five questions relevant to the text in their own words. Of course, they have to use the target words which are glossed the same with Task 1. So, a total involvement load index should be 3. In regard to Task 2 and Task 3, they initiate same involvement load yet pertain to different task types, the former being interpretive while the latter productive.

\subsubsection{Tests}

Texts in this study are composed of a vocabulary pretest, an immediate vocabulary test and a delayed vocabulary test. The pretest lists 16 potential target words from the reading material, requiring several top students from a fourth parallel class which will not participate in the experiment to tick out the words they have already known and write down their meanings. It is to facilitate selecting target words ensuring that the target words are unfamiliar to participants. The immediate and delayed vocabulary tests are conducted to investigate the effect of word acquisition and retention. Both tests are designed after Vocabulary Knowledge Scale (Parbakht \& Wesche, 1996) which is widely used as it can test learners' interpretive and productive knowledge of a word according to different levels of familiarity with the word. In case that the English version may create barriers to understanding the statements in the test and affect validity of the results, a Chinese version of VKS is adapted and here is an example:

1. I don't remember having seen this word before.

2. I have seen this word before, but I don't know what it means.

3. I have seen this word before, and I think it means

4. I know this word. It means

5. I can use this word in a sentence: (To write this sentence) 
Each target word is followed by four options. From total ignorance to the capability to use the word in a sentence both grammatically and semantically correct, the four options show a climactic relation in terms of different levels of familiarity with the word. The content of the delayed vocabulary test is almost the same with the immediate test but the sequence of the target word is changed deliberately in order to reduce lagging effect.

\subsection{Research Procedure}

The whole experiment consists of a pretest, a pilot study, reading along with completing reading tasks, immediate vocabulary test and delayed vocabulary test. The vocabulary pretest is first carried out among top students form one class which is not the experimental group to help determine target words. Then a pilot study is soon administered also in that class so as to make adjustment on difficulty of the reading material, choice of target words, task design, teacher instruction and so on. After improvement according to the results of the pilot study, the formal experiment is conducted. Three experimental groups participate in the study within the same time period of 30 minutes. The reading material along with tasks is distributed first and participants are given 20minutes to finish reading and relevant tasks. After that, the text and task papers are collected and immediate vocabulary test papers are assigned, the immediate test lasts for minutes. One week later, delayed vocabulary test is carried out without informing participants in advance. The delayed test has the same content with immediate test whereas the word order is changed and it also takes up 10 minutes. After the delayed test, the fifteen students again gather to have a conversation with the teacher.

\subsection{Data Collection and Analysis}

There are two groups of data needed to be collected in this study, one being the immediate vocabulary test scores and the other being the delayed vocabulary test scores. Considering the effectiveness of participants, task completion and their engagement in the task, several invalid samples are excluded, leaving 30 samples in each of the three task types. Whereupon, the immediate and delayed test scores of the 30 samples in each task are collected. The research data of present study are analyzed by SPSS 16.0. With regard to the first research question, one-way ANOVA approach is applied to explore whether there is any significant difference among the vocabulary test scores of the three groups in immediate and delayed test respectively. The effect of time on vocabulary retention is analyzed through Paired Samples T-Test. Then, as to the second research question, Independent Sample T-Test is used to inquire into the differences between group 2 (gap-filling after looing up target words in the dictionary) and group 3 (answering questions with original sentences) in both immediate and delayed test.

\section{$3 \quad$ Results and Discussion}

\subsection{The Influence of Reading Tasks with Different Involvement Loads on Incidental Vocabulary Acquisition}

This study applies the approach of One-Way ANOVA to test whether tasks inducing different involvement loads exert an influence on the vocabulary acquisition and word retention. As regard to a certain task, the effect of such kind of task on immediate acquisition and retention is testified and compared with Paired Samples T Test.

On the basis of the Involvement Load Hypothesis and current research findings ofL2 vocabulary learning, we derive several assumptions. Tasks with different involvement loads have effect on incidental vocabulary acquisition and word retention. Other factors being equal, tasks which induce higher involvement load result in better performance in immediate and delayed vocabulary test than tasks with lower involvement load. The descriptive statistics of the immediate and delayed test scores of the three groups are presented below: 
Table 3.1 Descriptive Statistics of Vocabulary Test Scores

\begin{tabular}{lccccc}
\hline & $\mathrm{N}$ & Minimum & Maximum & Mean & Std. Deviation \\
\hline Imm1 & 30 & 7.00 & 24.00 & 11.93 & 3.90 \\
Imm2 & 30 & 8.00 & 23.00 & 15.03 & 3.44 \\
Imm3 & 30 & 9.00 & 26.00 & 16.37 & 3.96 \\
Valid N (listwise) & 30 & & & & \\
\hline
\end{tabular}

Note: $\operatorname{Imm} 1=$ Immediate test score of Task 1

$\operatorname{Imm} 2=$ Immediate test score of Task 2

Imm $3=$ Immediate test score of Task 3

Table 3.2 Descriptive Statistics of Vocabulary Test Scores

\begin{tabular}{lccccc}
\hline & N & Minimum & Maximum & Mean & Std.Deviation \\
\hline Del1 & 30 & 3.00 & 16.00 & 9.50 & 3.41 \\
Del2 & 30 & 6.00 & 15.00 & 10.53 & 2.19 \\
Del3 & 30 & 9.00 & 24.00 & 13.23 & 3.74 \\
Valid N (listwise) & 30 & & & & \\
\hline
\end{tabular}

Note: Del1 $=$ Delayed test score of Task 1

Del2 $=$ Delayed test score of Task 2

Del3=Delayed test score of Task 3

From the Table 3.1 and Table 3.2, the mean scores of the three groups in the immediate vocabulary test are 11.93, 15.03 and 16.37 respectively, and in the delayed test, the mean scores are9.50, 10.53 and 13.23. They evidence that incidental vocabulary acquisition and word retention do exist after the implementation of reading tasks.

The mean scores of the three groups show that in the immediate test, students who participate in Task 2 (dictionary-consultation and gap-filling) and Task 3 (question and answer) perform better than students assigned with Task1 (reading comprehension). This is in evidence that tasks with higher involvement Load lead to better delayed word gains.

Table 3.3 One-way ANOVA of Three Groups in the Immediate Test

\begin{tabular}{lccccc}
\hline & Sum of Squares & df & Mean Square & F & Sig. \\
\hline Between Groups & 310.422 & 2 & 155.211 & 10.892 & 0.000 \\
Within Groups & 1239.800 & 87 & 14.251 & & \\
Total & 1550.222 & 89 & & & \\
\hline
\end{tabular}

Table 3.4 One-way ANOVA of Three Groups in the Delayed Test

\begin{tabular}{lccccc}
\hline & Sum of Squares & df & Mean Square & F & Sig. \\
\hline Between Groups & 222.956 & 2 & 111.478 & 10.992 & 0.000 \\
Within Groups & 882.333 & 87 & 10.142 & & \\
Total & 1105.289 & 89 & & & \\
\hline
\end{tabular}

As is indicated in Table 3.3, there exists significant difference among the immediate test results of the three tasks at the level of $0.05(\mathrm{sig} .=0.000<0.05)$. Similarly, in Table 3.4, the One-Way ANOVA shows significant difference among the delayed test results of the three tasks $($ sig. $=0.000<0.05)$. So it can be safely concluded that the test scores of the three groups have significant difference in both immediate and delayed tests, which verifies that tasks with different involvement loads bring about different effect on initial vocabulary learning and word retention. 
Table 3.5 Paired Samples T-Test of Three Groups

\begin{tabular}{ccccccccc}
\hline & & \multicolumn{3}{c}{ Paired Differences } & & \\
\cline { 2 - 5 } & & Mean & Std. Deviation & Std. Error Mean & t & df & sig.(2-tailed) \\
\hline Pair1 & Imm1-Del1 & 2.43 & 4.57 & 0.83 & 2.92 & 29 & 0.07 \\
Pair2 & Imm2-Del2 & 4.50 & 4.08 & 0.75 & 6.04 & 29 & 0.00 \\
Pair3 & Imm3-Del3 & 3.13 & 5.38 & 0.98 & 3.19 & 29 & 0.03 \\
\hline
\end{tabular}

From Table 3.5, we can see that all the mean differences between the immediate test and delayed test are significantly different. In group 1 , the mean score drops by 2.43 from the immediate test to the delayed test; in group 2, the mean score drops by 4.50; in group 3, the mean score drops by 3.13. Baddeley (2007) also claims, if the interval between the previous meeting and the present encounter with the target word is too long, the present encounter is considered more s the first encounter than a repetition. According to Schmidt (1990), the noticed input could probably be taken in and processed in an effective way and learners need to notice the information in the sensory register so as to transform the information into short-term memory thus preventing it from being forgotten, which is shown in the Information processing model. Generally, leakage of word gains in all three groups is high, which shows hat the retaining effect of vocabulary acquisition is far from satisfaction.

Therefore, the first research question can be answered. Reading tasks can facilitate incidental vocabulary acquisition and the acquisition effect varies due to different involvement loads of tasks. Tasks inducing higher involvement loads lead to better initial acquisition and word retention than those inducing lower involvement loads, yet with a poor retaining effect of vocabulary acquisition.

\subsection{The Influence of Different Task Types on Incidental Vocabulary Acquisition}

To be more specific, this part is to test whether the interpretive task and productive task can lead to significant difference between immediate acquisition and word retention, and which type appears superior in terms of word learning. Task 2 (dictionary-consultation and gap-filling task) and Task 3 (question and answer task) share the same involvement load index of 3 whereas their task type is opposite. One belongs to interpretive task and the other is productive task. The immediate vocabulary test scores and the delayed vocabulary test scores are analyzed through Independent Samples T Test.

Table 3.6 Independent Samples T-Test for Task Type in Immediate Vocabulary Test

\begin{tabular}{cccccccc}
\hline & Task Type & $\mathrm{N}$ & Mean & Std. Deviation & Std. Error Mean & $\mathrm{t}$ & Sig.(2-tailed) \\
\hline Immediate & Task 2 & 30 & 15.033 & 3.438 & 0.627 & -1.392 & 0.169 \\
Test Score & Task 3 & 30 & 16.367 & 3.960 & 0.723 & & \\
\hline
\end{tabular}

In Table 3.6, the mean scores of Task 2 and Task 3 show that the interpretive task and the productive task which induce relatively high involvement load both can obviously lead to learners' immediate vocabulary acquisition. Independent Sample T-Test results indicate that there is no significant difference in mean scores of the two tasks (Sig. $=0.169>0.05$ ), which proves that the involvement load being equal, the factor of task type does not trigger significant difference in immediate vocabulary gains. This result corresponds with the hypothesis of Hulstijn \& Laufer (2001), stating that the effect of initial memory for interpretive task and productive task is not that different when the involvement load is the same.

Table 3.7 Independent Samples T-Test for Task Type in Delayed Vocabulary Test

\begin{tabular}{cccccccc}
\hline & Task Type & $\mathrm{N}$ & Mean & Std. Deviation & Std. Error Mean & $\mathrm{t}$ & Sig.(2-tailed) \\
\hline Delayed & Task 2 & 30 & 10.533 & 2.192 & 0.401 & -3.412 & 0.001 \\
Test Score & Task 3 & 30 & 13.233 & 3.738 & 0.682 & & \\
\hline
\end{tabular}

In table 3.7, the mean scores of Task 2 and Task 3 are 10.53 and 13.23, showing that the interpretive task 
and the productive task which induce relatively high involvement load can also lead to learners' vocabulary retention. The Sig. $(=0.001<0.05)$ proves that the involvement load being equal, task type serves as a factor generating significant difference in delayed vocabulary gains.

In conclusion, the second research question can be answered that with the involvement load being equal, the interpretive task and the productive task can lead to significant difference in delayed vocabular gains but not in immediate vocabulary gains. The productive task facilitates better delayed gains than the interpretive task whereas the retention effect of both task types is not so favorable.

\section{Conclusions}

This study aims to investigate the effects of different reading tasks on incidental vocabulary acquisition of senior high school students from perspective of involvement load and task type. It intends to figure out how reading tasks with different involvement loads affect immediate word gains and delayed word gains and how reading tasks of different types influence initial vocabulary acquisition and retention.

We could find that, based on the Input Hypothesis, the reading material and reading tasks serves as comprehensible input to facilitate vocabulary acquisition, accounting for a good acquisition effect. As for the effect of reading tasks on acquisition, dictionary-consultation and gap-filling task along with question and answer task leads to better initial vocabulary acquisition and word retention than reading comprehension task, which is in consistent with the Involvement Load Hypothesis as tasks with higher involvement loads can be more conducive than tasks with lower involvement loads to incidental vocabulary acquisition. Besides, the input-based task induces certain level of mental processing and leads to a relatively high vocabulary gains in terms of immediate acquisition. According to Output Hypothesis proposed by Swain (1985), such kind of micro-level syntactic processing helps language acquisition more. In other words, output-based task requires a higher level of language proficiency which leads learners to unconsciously touch upon in-depth knowledge of target words. Besides, the key to word retention lies in deep processing of lexical relevance, as is supported by Craik \& Tulving (1975). The output-based task in this study involves deep processing of word knowledge required for sentence-making, contributing a lot to retention of the target words.

Acknowledgements. This word was supported by 2018 Research project on humanities and social sciences of Henan provincial department of education "The study on the cognitive mechanism of vocabulary acquisition for college English learners" (2018-zzjh-113), 2017 Henan provincial philosophy and social science planning project "The neurolinguistic research on the acquisition of vocabulary with high level English learners in Henan province" (2017BYY004), and graduate students' education teaching reform and practice project of Henan province in 2017(2017SJGLX048Y).

\section{References}

1. Baddeley, A. 2007. Working memory, thought, and action[M]. Oxford: Oxford University Press.

2. Craik, F. I. M \& E. Tulving. 1975. Depth of processing and the retention of words in episodic memory[J]. Journal of Experimental Psychology: General 104(3): 268-294.

3. Ellis, N. C. \& A. Beaton. 1993. Psycholinguistic determinants of foreign language vocabulary learning[J]. language Learning (4):559-617.

4. Ellis, R. 2003. Task-based Language Learning and Teaching[M]. Oxford: Oxford University Press.

5. Hulstijn, J. H \& B. Lauger. 2001. Some empirical evidence for the involvement load hypothesis in vocabulary acquisition[J]. Language Learning 51(3):539-558.

6. Laufer, B \& J. Hulstijn. 2001. Incidental vocabulary acquisition in a second language: The construct of task-induced involvement[J]. Applied Linguistics 22(1):1-26.

7. Nagy, W. E., P. A. Herman \& R. C. Anderson. 1985. Learning words from context[J]. Reading Research Quarterly $20(20): 233-253$.

8. Paribakht, T. S. \& m. Wesche. 1996. Enhancing vocabulary acquisition through reading: A hierarchy of text-related exercise types[J]. The Canadian Modern Language Review 52(2):155-178.

9. Schmide, R. 1990. The role of consciousness in second language learning[J]. Applied Linguistics 11:129-158. 
10. Swain, M. 1985. Communicative competence: Some roles of comprehensible input and comprehensible output in its development[A]. In S. Gass \& C. Madden(eds.). Input in Second Language Acquisition[C]. Rowley, Mass: Newbury House. 235-256. 